\title{
AN EMPIRICAL STUDY OF CUSTOMER LOYALTY TOWARDS RADIO STATIONS IN MALAYSIA
}

\author{
S. F. Yeo*, C. S. Cheah, L. F. S. Wee, P. K. Tan, T. H. Chee \\ Faculty of Business, Multimedia University, Melaka, Malaysia \\ *yeo.sook.fern@mmu.edu.my
}

\begin{abstract}
This study delves into the radio broadcasting industry and examines the effects of brand loyalty towards radio station among the undergraduate students of Malaysia. It looked into what brand loyalty is in the marketing field and how it is applied in the radio broadcasting industry. It will examine several factors that influence the listener's brand loyalty towards their favourite radio station. This study was conducted using primary data research and secondary data research. Data from 312 respondents were used in the statistical analysis to determine the relationship between the factors that influence the consumer's brand loyalty towards their favourite radio station. This research would benefit other researchers, marketers, consumers and also the radio broadcasting industry as a whole. The results gathered from the surveys of 312 individual respondents concluded that the independent variables, which are engagements and brand awareness had a positive and significant influence on brand loyalty towards radio station. On the other hand, the remaining three independent variables had no significant and positive impact on brand loyalty towards radio station.
\end{abstract}

Keywords: Empirical Study, Customer Loyalty, Radio Stations

\section{INTRODUCTION}

The radio broadcasting industry was a silent contender in the current world of fast social media and curated content. Radio was actually the most listened to media in 2016 , and was therefore a great avenue for marketers to put forth their marketing ideas through the medium of audio only. More people are connected to radio than ever before, they are engaged by talk shows, music, news and events. They are also engaged with the radio station through identifiable broadcasters and are emotionally engaged with the content. This study delves into the radio broadcasting industry and examines the effects of brand loyalty towards radio station among the undergraduate students of Malaysia. This study looked into what brand loyalty is in the marketing field and how it is applied in the radio broadcasting industry. It will examine several factors that influence the listener's brand loyalty towards their favourite radio station. This study was conducted using primary data research and secondary data research. Data from 300 respondents were used in the statistical analysis to determine the relationship between the factors that influence the consumer's brand loyalty towards their favourite radio station. This research would benefit other researchers, marketers, consumers and also the radio broadcasting industry as a whole. The results gathered from the surveys of 312 individual respondents concluded that the independent variables, which are engagements and brand awareness had a positive and significant influence on brand loyalty towards radio station. On the other hand, the remaining three independent variables had no significant and positive impact on brand loyalty towards radio station.

"Radio continues to be a popular medium as indicated by the high reach. Besides, radio exposure has also proven to create a positive affinity for bottom-line sales," said Ting. "Based on a recent Nielsen sales effect study conducted in the U.S. which examined radio's return on ad spend across four retail categories (Department Stores, Mass Merchandisers, Home Improvement Stores and Quick Service Restaurants), it was found that every dollar spent in radio advertising could generate up to US\$17 of revenue from listeners who were exposed to radio ads" (Nielsen, 2016).

LITERATURE REVIEW

Consumer Loyalty

Submit Date: 05.07. 2018, Acceptance Date: 27.08.2018, DOI NO: 10.7456/1080SSE/108

Research Article - This article was checked by Turnitin

Copyright (C) The Turkish Online Journal of Design, Art and Communication 
Customer loyalty can be classified as the result of consistently positive emotional experience, physical attribute-based satisfaction and perceived value of an experience which includes either products or services. Furthermore, consumer loyalty can also be considered as a pattern of consumer behavior where consumers become committed to brands and make repeat purchases from the same brands over a period of time. One of the distinctive factors of loyal customers is their tendency to consistently purchase products from their preferred brands, regardless of convenience or price. Companies often use different marketing strategies to cultivate loyal customer, including loyalty programs or trials and incentives (Kotler et al., 2016). Studies by Jin et al. (2016) found that service quality will not have an impact towards customer loyalty. Akın (2012) consider that loyalty is not the same as repeated purchasing because loyalty depends upon some other factors like brand characteristics, customers' preferences, existence of alternative product / services. However, satisfaction and loyalty are closely aligned while satisfied and loyal customer is able to increase companies' success significantly (Khan, 2012).

\section{Advertisement}

According to the American Marketing Association (AMA) in 2013, advertisement can be defined as the act of and organization or someone, who pays for the right to display his or her own message of their own choosing on a particular space or during a particular time. This usually come is some form of mass media with the aim to persuade people. Advertising is also an audio or visual form of marketing communication that which uses an openly sponsored, non-personal message to promote or sell a product, service or idea. Sponsors of advertising are often businesses who wish to promote their products or services (Calder et al., 2015). According to Ivanic et al. (2014), audio advertisements are designed to convince a consumer to purchase a product or service. Studies also shows that there was a significant amount of emotion when the listeners of radio station were engaged with the advertisements (Khan, 2012).

H1: There is a significant and positive relationship between radio advertisements and the brand loyalty towards the radio station.

\section{Broadcasters}

A broadcaster is a communications professional who works in the radio and television industry as a journalist or an announcer. Furthermore, the job of the broadcaster may further be divided into reporters, correspondents or analysts (Foster \& Marshall, 2015). The broadcaster's duty as a reporter or correspondent include investigating crimes, human interest stories or disasters; arranging interviews with witnesses or experts; determining the focus, structure and length of stories; researching, writing and reviewing story copy; delivering stories on location and in the studio (Napoli, 2011). On the other hand, an analyst would select stories and events for deeper analysis and interpretation, develop and organize their perspective on those stories and present their observations on air such as on the radio station. As an announcer the broadcaster reads news stories and program schedules, interview guests, lead panel discussions or provide commentary at live events (Rodero, 2013). Bosch (2014) conducted a study in South Africa revealed that a lot of listeners were very attentive to the radio station because of the race or ethic of the broadcaster of their radio station, this in turn created a bond between the audience and the radio broadcaster. Furthermore, another attribute of a broadcaster is their personality (Associates, 2002) which may not always be liked by everyone, so in in turn it may not play significant role in creating brand loyalty for the listeners towards radio stations.

H2: There is a significant and positive relationship between broadcasters and the brand loyalty towards the radio station.

\section{Engagement}

Engagement can be defined as the attention and interactivity that consumers is engaged to a brand, product or service (Kotler et al., 2016). According to Nierenberg et al. (2017), consumer engagement can also be when the brand and the consumers connect. He also explained that experiential marketing can be considered an engagement to the consumers because it is a live and a one-on-one interaction that allow consumers to create connections with brands. When this works well, the consumers will 
continue to seek and demand one-on-one, shareable interaction with a brand. This may just be a small part of the engagement of the radio station, but this is a highly crucial part in listener engagement since more than half the time on the radio advertisement is being played to the listener (Babich, 2014). Events are also another important factor in terms of engagement. Furthermore, this has only been used in recent years and was not even a factor in the past (Foster \& Marshall, 2015). A study done by Bosch (2014) measures the level of engagement by the means of the emotional level, which the listeners are engaged with during the listening period. In the result, it was show that the more emotionally the listeners were engaged with the radio station, the higher the engagement level it is with the radio station.

H3: There is a significant and positive relationship between engagement and the brand loyalty towards the radio station.

\section{Music Genre}

Music is an art from or cultural activity which uses medium in terms of sound and silence, the most common elements of music are pitch, rhythm, dynamics and the sonic qualities of timbre and texture. Moreover, music has many styles or types of music which may emphasize, deemphasize or omit some of these elements (Jones et al., 1996). Music can then be divided into genre and genre can even be further divided into subgenre. This is an important point because the genre will determine the type of audience the radio station would attract and connect (Babich, 2014). There are hundreds of genres and subgenres under music, and all of these are not only relevant but essential in the composition of the personality of the radio station and its impression on the listeners (Music Genre List, 2018). Furthermore, music is also a medium which carries a lot of emotional feeling, which listeners use to connect and engage with. In the results of a study done by Burkholder (1991), it was shown that the level of engagement is an important component in building a strong and lasting loyal relationship with the radio stations.

H4: There is a significant and positive relationship between engagement and the brand loyalty towards the radio station.

\section{Brand Awareness}

Brand awareness is the strength of the brand node in memory, this refers to how easy it is for the consumer to remember the brand (Keller \& Lehmann, 2006). However, brand awareness consist of two components which are brand recognition and brand recall. Brand recognition is the consumer's ability to confirm prior exposure to the brand when given the brand as a cue. One way to identify the consumer's brand recognition is to see if they are able to identify correctly the brand as being seen or heard before (Kim \& Kim, 2016). Duong (2014) has described brand awareness as an essential part in building recognizing the brands and then creating lasting relationship to start building brand loyalty. From his results, it was shown that brand attitude makes up the part of how the consumer evaluates the brand from their perspective and it's an important role in determining the brand awareness of the consumer or the listener (Keller \& Lehmann, 2006). Besides this, a study by Nielsen (2016) showed that almost all Malaysians are aware of every major radio station in the country and is also actively engaged with it. The study showed a significant increase in radio station listeners since 2012.

H5: There is a significant and positive relationship between brand awareness and the brand loyalty towards the radio station.

\section{METHOLODOGY}

This study was conducted through the distribution of questionnaires. Mail questionnaire and online questionnaire methods were employed in this study. The unit of analysis for this study is Malaysian radio listeners. Non-probability purposive sampling was used in the study to identify the respondents. Results from the reliability analysis show that the Cronbach Alpha value for all the variables involved in this study range from 0.987 to 0.667 . Engagement has recorded the highest Cronbach Alpha value of 0.987 , while advertisement has the lowest Cronbach Alpha value of 0.667. The F-value is 21.905 and the $p$-value is 0.000 , which is less than $0.05(\mathrm{p}<0.05)$. 
Furthermore, the overall regression model with the five predictors are advertising, broadcasters, engagement, music and awareness are defined as variations in brand loyalty on radio station.

Table 1. Reliability analysis

\begin{tabular}{|c|c|}
\hline Variable & Cronbach Alpha \\
\hline Brand Loyalty & 0.714 \\
\hline Advertisement & 0.667 \\
\hline Broadcasters & 0.823 \\
\hline Engagement & 0.987 \\
\hline Music & 0.754 \\
\hline Awareness & 0.689 \\
\hline
\end{tabular}

\section{RESULTS AND DISCUSSION}

Questionnaires were distributed among 317 respondents. 151 printed surveys were distributed, 5 went missing. The online survey made up the majority of 166, all of whom responded accordingly. This totaled only 312 respondents who responded to our questionnaires out of 317 , totaling to a $98 \%$ response rate for this research. There is a total of $129(41.3 \%)$ male respondents and 183 (58.7\%) female respondents. Among these respondents, 33\% of the respondents are age between 18 to 20 years old. Besides, the highest number of respondents come from the Chinese ethnic group with a total of 226 respondents whereas the Indian ethnic group has recorded the least number of respondents of only 34. Majority of the respondents preferred to listen to the English radio station (47.8\%) where Hitz.FM (66.7\%) has been the most favourite radio station among these respondents. Furthermore, $51.9 \%$ (162) responded by agreeing that they listen to the radio station on a daily basis and $87(27.9 \%)$ of them will spend approximately 20 minutes on listening to radio.

Table 2 shows the multiple regression analysis results where engagement and awareness shows significant relationship towards loyalty towards radio stations in Malaysia, which the p-values for all two variables are less than 0.05 . This study provides the same results with the previous study and the findings indicate that listeners, who are loyal to the radio stations thinks that engagement and awareness are important factors. On the other hand, the broadcasters, music and advertising shows that there is no significant relationship to brand loyalty on radio stations in Malaysia. This indicated that the respondents are not putting much expectations on the broadcasters, music and advertising in order to stay loyal to their favourite radio stations.

Table 2. Coefficients table

\begin{tabular}{|c|c|c|c|}
\hline Variables & $\mathbf{t}$ & Sig. & Results \\
\hline Broadcasters & 1.565 & .119 & Not supported \\
\hline Engagement & 3.870 & .000 & Supported \\
\hline Music & -0.524 & .601 & Not supported \\
\hline Awareness & 5.730 & .000 & Supported \\
\hline Advertising & 1.140 & .255 & Not supported \\
\hline
\end{tabular}

\section{CONCLUSION}

Results from this study has shown that engagement and awareness are the key factors on brand loyalty towards the radio stations in Malaysia. Based on the data gathered from the research, the researchers have established that some implication that might be helpful in assisting the radio industry in better understanding the culture of radio listening among Malaysians, this may help 
them in creating better and more engaging content that suits the current demographic of Malaysians. Currently, there are more radio stations than ever before to choose from in Malaysia alone. As a result, it is necessary for the radio industry to improve their content creation and management while executing different marketing strategy to increase their brand loyalty to their target market. The research that was conducted showed that not all variables (advertising, broadcasters, music, awareness and engagement had strong relationship with the brand loyalty towards radio stations). Conclusively, understanding these factors can help the radio industry and also its audiences to create beater content. Hence, the findings from this research will provide implications for the radio industry as a whole.

\section{REFERENCES}

Akın, E. (2012). Literature review and discussion on customer loyalty and consciousness. European Journal of Economics, Finance and Administrative Sciences, 51, 158-173.

Associates, D. (2002). Personality tendencies. University of Michigan Health Systems.

Babich, B. (2014). Adorno's radio phenomenology: Technical reproduction, physiognomy and music. Philosophy and Social Criticism, 40(10), 957-996.

Bosch, T. E. (2014). Commercial music radio, race and identity in South Africa. Media, Culture and Society, 36(7), 901-915.

Burkholder, J. P. (1991). Musical time and continuity as a reflection of the historical situation of modern composers. Journal of Musicology, 9(4), 411-429.

Calder, B. J., Isaac, M. S., \& Malthouse, E. C. (2015). How to capture consumer experiences: A context-specific approach to measuring engagement: Predicting consumer behavior across qualitatively different experiences. Journal of Advertising Research, 55(4), 1-14.

Duong, J. (2014). Western European consumer perception of a Chinese brand: An examination of Huawei. https://www.grin.com/document/300180.

Foster, P., \& Marshall, W. (2015). Tales of the tape: cassette culture, community radio, and the birth of rap music in Boston. Creative Industries Journal, 8(2), 164-176.

Ivanic, A. S., Bates, K., \& Somasundaram, T. (2014). The role of the accent in radio advertisements to ethnic audiences: Does emphasizing ethnic stereotypes affect spokesperson credibility and purchase intention? Journal of Advertising Research, 54(4), 407-420.

Jin, S. T. T., Ling, T. C., \& Fern, Y. S. (2016). What are the attractiveness aspects that influence customer loyalty to homestays? A study in Taiwan. Jurnal Pengurusan (UKM Journal of Keller, K. L., \& Lehmann, D. R. (2006). Brands and branding: Research findings and future priorities. Marketing Science, 25(6), 740-759.

Khan, O. (2012). Towards understanding customer loyalty: An empirical study on emotional attachment. International Journal of Innovations in Business, 1(3), 241-267.

Management), 48, 201-218.

Jones, H. S., McKenzie, R., Glare, P. G., \& Thompson, A. A. (1996). A Greek-English Lexicon. Clarendon Press.

Kim, D. K., \& Kim, M. (2016). Influence of brand awareness and brand attitude on purchase. Journal of Marketing Thought, 3(1), 16-27.

Kotler, P., Kartajaya, H., \& Setiawan, I. (2016). Marketing 4.0: Moving from traditional to digital. John Wiley and Sons.

Music Genre List. (2018). The most comprehensive list of genres of music available on the Internet. http://www.musicgenreslist.com/.

Napoli, P. M. (2011). Retransmission consent and broadcaster commitment to localism. CommLaw Conspectus, 20, 345-362.

Nielsen, R. K. (2016). The business of news. Sage.

Nierenberg, B., Alexakis, G., Preziosi, R. C., \& O'Neill, C. (2017). Workplace happiness: An empirical study on well-being and its relationship with organizational culture, leadership, and job satisfaction. International Leadership Journal, 9(3), 2-23.

Rodero, E. (2013). The perception of a broadcasting voice. US-China Education Review, 4, 225-230. 